\title{
Application of open network knowledge in data mining and Information retrieval
}

\author{
Deng Ruren ${ }^{1, a}$, Wu Yinghuan ${ }^{2, b}$ \\ ${ }^{1}$ Jiangxi Science \& Technology Normal University, Nanchang, Jiangxi, 330013, P.R. China \\ ${ }^{2}$ Nanchang Institute of Technology, Nanchang, Jiangxi, 330013, P.R. China \\ a37453477@qq.com, 'buanl2016@126.com
}

Keywords: Computer, Logistics simulation technology, Enterprise decision, Application

\begin{abstract}
With the development of science and technology, the use of computer simulation technology has become increasingly widespread, and has played an important role in the decision-making of enterprises in our country. In the traditional enterprise decision-making, because of the lack of data and the accuracy of the simulation system, the fault of the enterprise's decision is often caused. The use of computer logistics simulation technology, comply with the needs of the development of the enterprise. This paper analyzes the necessity of the application of computer simulation technology in enterprise decision-making, and analyzes its application status and development prospects.
\end{abstract}

\section{The necessity of computer simulation technology for enterprise decision making}

The application of computer simulation technology can not only save money and reduce the cost of system design, but also improve the accuracy of the design, and then improve the feasibility of the logistics system. As an important basis for enterprise decision making, the computer logistics simulation system will be produced in the same time, and can be used to analyze the details of the system. In addition, the computer simulation technology for enterprise decision making is necessary, but also reflected in the following three aspects:

To meet the needs of enterprise logistics. In the process of modern enterprise production, logistics almost runs through the whole process of production, and has gradually become an important part of the production process. Enterprise production process in the required parts, raw materials, etc. are required to pass through the logistics to the production line, and with the process of production in order to enter the production of various links. In this process, the raw material itself has been processed, but also produce more than material and waste, the production of the product was sent to the warehouse again, so far, the enterprise production logistics to go through a process. In the traditional production management, the influence of logistics on the production efficiency of the enterprise has not been fully considered. The introduction of computer simulation technology is very important to improve the efficiency of logistics production.

To meet the needs of enterprise supply logistics. In order to ensure the continuity of the production process, we need to carry out the logistics supply activities of the parts, materials and combustion. The development of the modern enterprise is facing the great pressure of competition, the supply logistics of the enterprise also put forward higher requirements. The supply logistics of the enterprise is not only to provide guarantee for the normal production and operation of the enterprise, but also to keep the low cost. This requires the use of computer simulation technology to solve the logistics supply mode, material inventory and supply network and other issues.

To meet the needs of the enterprise sales logistics. For enterprises, the sales logistics is the way to achieve the operating profit, through the sales logistics, to the production of products sold to the user. Relative to the production and supply logistics, the sales logistics service is stronger, its purpose is to meet the needs of buyers, to complete the sales activities. At present, the biggest problem facing the development of the enterprise is the wide range of space, and the cost of logistics is not effective. The introduction of computer simulation technology can solve this problem to a certain extent. 


\section{The status quo of the application of computer simulation technology in enterprise decision making}

The introduction of virtual instrument. Computer simulation technology is a comprehensive high-tech technology, which includes the multimedia technology, modern information communication technology, control technology, etc., its application is the use of mathematical model of the system to achieve the logistics simulation system research, analysis and design, etc.. On the one hand it has been applied to the planning and design of the automatic logistics system. On the other hand, it is widely used in aircraft, ships, nuclear power plants and other precision instruments. In terms of the composition of the equipment, the computer technology is the core of the virtual device, and the function of the mechanical instrument is realized by combining the functions of hardware and software. On the use of equipment, the use of computer graphics capabilities, the construction of human-computer interaction interface, the use of programming language to achieve the control of virtual instruments, complete data acquisition, analysis, judgment and other functions.

In essence, the use of virtual equipment is to play the advantages of the computer, to achieve the extension of the function of the traditional equipment. Data acquisition card system, VXI system and CPIB system for the current more commonly used system, but also includes any combination of these three application systems. The device is divided into two aspects: hardware system and software system. The main function of the hardware system is to realize the input and output of the signal, and the software system is the core of the whole device. Even to say that the software is the instrument. In actual use process, the user can according to the actual demand, the system of the virtual equipment design, in order to better meet the actual application needs. Through the comprehensive use of computer software and hardware system, relative to the traditional equipment, virtual equipment in data collection and collation. Express and convey a great advantage in such aspects.

The main computer logistics simulation software. At present, the main use of software in the computer simulation technology includes Stroam, ShowFlow, RaLC, Automod and so on.

First, Le Dragon (RaLC). The software is developed by Japanese AIS company. The main purpose of this software is to realize the intelligent and simple, the operation staff can realize the creation of logistics model by simple operation. In short, the RaLC series software is a tool type software, its role is to build three-dimensional logistics distribution center model based on the computer, to realize the logistics process and the simulation of experimental activities.

Second, ShowFlow. It is a simulation software developed by the British scientists, the role of the modern manufacturing enterprises and professional logistics enterprises to provide logistics simulation, logistics animation simulation and logistics data analysis of the function. The advantage of ShowFlow is that it can analyze the output, and get the bottleneck of logistics, forecast and evaluate the utilization efficiency of the resources in advance. In addition, the software can provide a reference for the enterprise's investment decision, analysis and evaluation of the scientific nature of the manufacturing system, comprehensive consideration of the manufacturing plan, and to seek the best solution.

Third, Stroam is derived from a simulation software in japan. This software takes Sil-Tools as the foundation, therefore, the operation of the software is different from the general software. The biggest feature of the software is that, in the Japanese environment, from the command group to select the control logic of the various devices, and on the basis of the control logic of the neat arrangement.

Fourth, Automod. Automod's developers are the United States (B\&A), compared with other virtual logistics simulation software, the software design is more mature. In this system, we need to create object entities, and we need to write a different language to realize the simulation of the operation process. The use of the software is relatively complex, in the process of logistics simulation, all objects need to create the command language, so the technical staff of the workload is relatively large, virtually increased the cost of virtual simulation technology. 


\section{Application prospect of computer logistics simulation technology}

With the continuous development of science and technology, computer simulation technology has been used in the field of electric power, transportation, military and other fields, and with the continuous development of computer technology, the use of depth and breadth will be further improved.

In the development of the future, the application of computer simulation technology in the logistics system will focus on the development of the two aspects. One is to shorten the logistics center planning and design cycle, the two is to realize the continuous optimization of the logistics plan. In recent years, human computer interface has been widely used, in the future production, not only can quickly obtain the information of production equipment, but also to realize the operation of the device to determine the status of the system to run the state of the feedback. By changing the parameters of the input, the impact of fluctuations in the production of the logistics system, and then a comprehensive consideration of various factors that may occur, and to develop preventive measures in advance.

The construction of the logistics system can provide a unified communication platform for the manufacturers, wholesalers, retailers and so on. Therefore, the function of the logistics system service platform will include the following aspects: first, to realize the logistics data management. Management of logistics data includes data collection, collation, transfer, storage and analysis. Second, the realization of the enterprise logistics process of modern management. Third, maintain good customer relationship. Fourth, realize the intelligent processing of emergency. Fifth, to achieve the sharing of information. Sharing information can effectively reduce the inconvenience caused by poor communication.

\section{Conclusion}

All in all, in the process of enterprise development, the successful logistics system can bring good economic benefits for the enterprise. In the current technology environment, the computer logistics virtual simulation technology is an effective way to build a good logistics system, which can save the human, material and financial resources in the process of enterprise development. Therefore, we have reason to believe that, with the development of science and technology and the continuous improvement of computer logistics virtual simulation technology, its development prospects will be more broad.

\section{References}

[1] L.J. Zhu, in the profit of the people. Talk about computer simulation technology in the logistics application of. Heilongjiang scientific and technological information, 2008 (24).

[2] Gong Jianhong, Chen Zixia. The status quo and development of logistics simulation software. Journal of Zhejiang Gongshang University, 85, 2007 (4).

[3] Jinhai. Computer simulation technology in the modern logistics application of. logistics technology, 2012 (9). 